\title{
Health-seeking behaviour of people living with HIV/AIDS and their satisfaction with health services provided at a tertiary care hospital, Karachi, Pakistan
}

Abdul-Qadir Bhutto ${ }^{7}$ and Nighat Nisar ${ }^{7}$

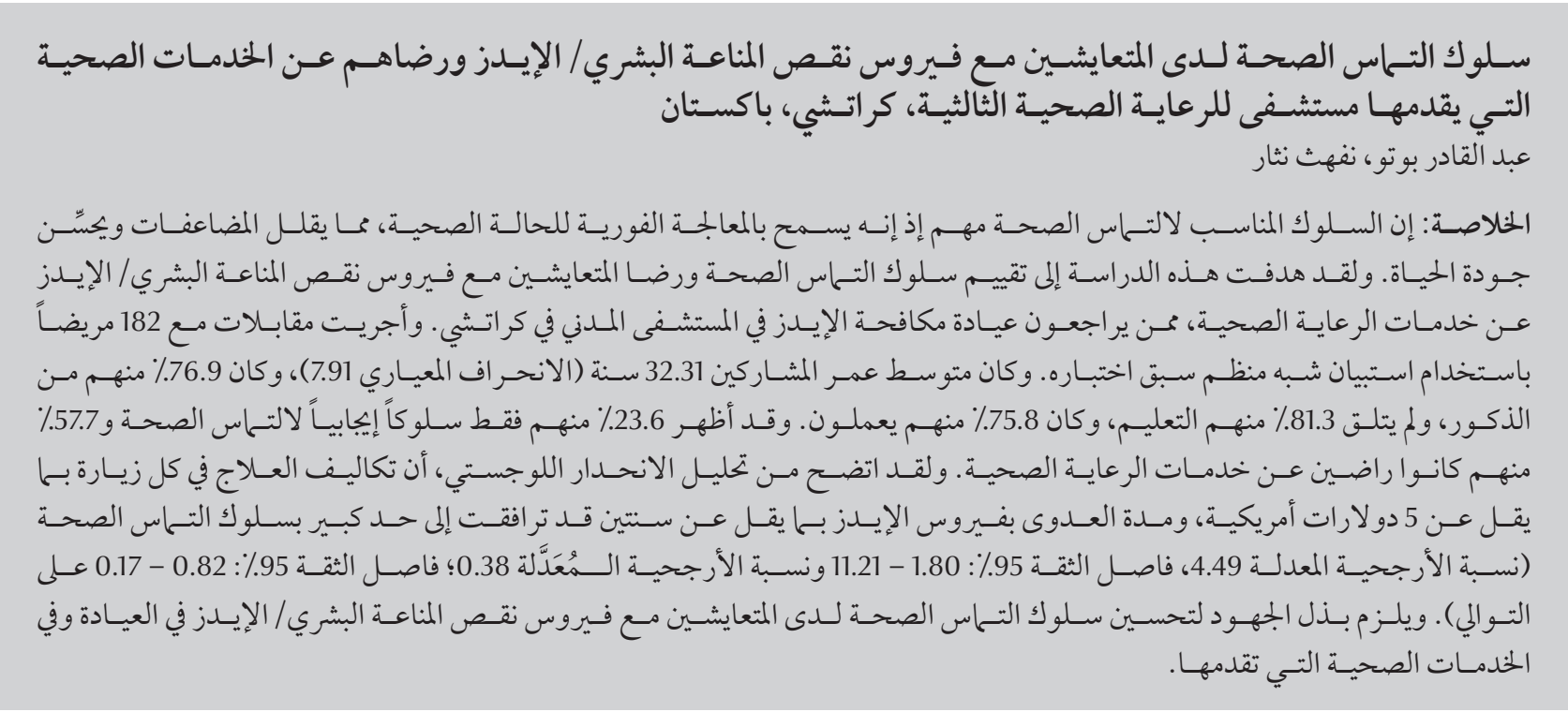

ABSTRACT Appropriate health-seeking behaviour is important as it allows prompt treatment for a condition and this can reduce complications and improve quality of life. This study aimed to assess the health-seeking behaviour and satisfaction with health care services of people living with HIV/AIDS attending the HIV/AIDS clinic of the Civil Hospital in Karachi. A total of 182 patients were interviewed using a pretested semi-structured questionnaire. Mean age of the participants was 32.31 (SD 7.91) years, $76.9 \%$ were male, $81.3 \%$ had no education and $75.8 \%$ were employed. Only $23.6 \%$ showed positive health-seeking behaviour and $57.7 \%$ were satisfied with the health care services. In logistic regression analysis, the cost of treatment per visit $<$ US\$ 5 and duration of HIV infection $<2$ years were significantly associated with health-seeking behaviour. Efforts are needed to improve the health-seeking behaviour of people living with HIV/AIDS at the clinic and the health services offered.

Propension des personnes vivant avec le VIH/sida à se faire soigner et degré de satisfaction à l'égard des services de santé qui leur sont proposés dans un hôpital de soins tertiaires, à Karachi (Pakistan)

RÉSUMÉ Des comportements adaptés en matière de recherche de soins sont importants car ils permettent la mise en place d'un traitement rapide de la maladie et peuvent limiter les complications ainsi qu'améliorer la qualité de vie. La présente étude avait pour objectif d'évaluer la propension à se faire soigner ainsi que la satisfaction en matière de services de soins de santé des personnes vivant avec le VIH/sida en consultation à la clinique spécialisée dans la prise en charge du VIH/sida de l'hôpital civil de Karachi. Un total de 182 patients ont été interrogés au moyen d'un questionnaire semi-structuré pré-testé. L'âge moyen des participants était de 32,31 ans (ET 7,91), 76,9 \% étaient des hommes, 81,3\% n'avaient aucune instruction et 75,8 \% avaient un emploi. Seulement 23,6 \% affichaient une propension à se faire soigner, et 57,7 \% étaient satisfaits des services de soins santé offerts. L'analyse de régression logistique a montré qu'un coût du traitement par visite inférieur à 5 dollars et qu'une durée de l'infection par le VIH de moins de deux ans étaient associés de façon significative à des comportements positifs en matière de soins. Des efforts sont requis pour augmenter la propension des personnes vivant avec le VIH/sida à se faire soigner ainsi que pour améliorer les services proposés à la clinique. 


\section{Introduction}

Human immunodeficiency virus (HIV) and acquired immunodeficiency syndrome (AIDS) are a major global public health problem. The worldwide efforts to manage the HIV and AIDS pandemic have been increased because the virus is spreading with greater speed (1). In 2012, about 33.4 million people were living with HIV worldwide (1). In December 2014 in Pakistan, an estimated 91340 people (range 61 000-128 000) were living with HIV and another 15606 (range 7 000-33 000) were newly infected with HIV (2). The overall prevalence of HIV among 15-49-year-olds in Pakistan was $0.8 \%(2)$.

The main modes of HIV transmission reported in south Asia and Pakistan are sexual transmission and reuse of contaminated syringes (1). In south Asia, individuals infected with HIV are usually unaware of the disease and unable to detect symptoms in the early stages. Before diagnosis and seeking proper health care, patients may have already received health care from spiritual or faith healers, which delays diagnosis and proper treatment. This lack of awareness of the disease results in the majority of HIV-infected persons not seeking medical help until the condition has worsened leading to various complications of HIV. Treating the disease at this stage with causes a financial burden to the individual and family and this has been reported as a major constraint in seeking proper medical care (3).

The accessibility to services, information and educational initiatives concerning HIV and AIDS does not guarantee access of a person to proper treatment. Health-seeking behaviour of an individual determines their approach towards receiving proper treatment for a disease. Research on cultural aspects supports the importance of knowledge regarding the disease and the health-seeking behaviour of patients (4). According to a study conducted in India on $160 \mathrm{HIV-infected} \mathrm{patients,}$ self-motivation for HIV/AIDS medical treatment was found in only $3.8 \%$ of the patients (5). Other significant factors related to the HIV-infected person and their access to treatment reported in the study were lack of information, prejudice and an unsupportive attitude of health care providers, unavailability of a patient's medical history/reports from previous consultations, legal status and use of traditional medicine (5). It is therefore important to determine the health-seeking behaviour of HIVinfected persons and their satisfaction with the health services provided so that their needs and preferences can be better addressed (6).

Previous research studiesin Pakistan have been conducted on knowledge, attitude and practices regarding HIV/ AIDS, prevalence and risk factors of HIV/ AIDS and education and counselling regarding HIV/ AIDS $(7,8)$ but none has looked at the health-seeking behaviour of persons living with HIV. The present study therefore aimed to assess the health-seeking behaviour of persons living with HIV at a tertiary care hospital in Karachi, Pakistan and their satisfaction with the health care services provided.

\section{Methods}

\section{Study design and setting}

This was a cross-sectional study conducted in the HIV/AIDS clinic of the Civil Hospital, Karachi, Pakistan from August 2013 to February 2014. The Civil Hospital is a 1900 -bed public sector tertiary care teaching hospital providing health care services to people of Sindh and Baluchistan. About 5000 patients have been registered in the HIV/AIDS clinic and daily turnover at the outpatient clinic is about 50 patients. The clinic offers registration of HIV patients, follow up in the outpatient clinic, treatment and laboratory facilities.

\section{Sample size and sampling}

The population of interest consisted of both male and female people living with HIV/AIDS over the age of 18 years attending the HIV/AIDS health care centre of the hospital. The study participants were enrolled in the study through purposive sampling. The sample size of 182 was calculated using the equation $P(1-P) / \mathrm{d}^{2}$, assuming a proportion $(P)$ of self-motivated health-seeking behaviour of $13.8 \%$ (5) with $95 \%$ confidence interval and 5\% margin of error.

\section{Data collection and tools}

A questionnaire was designed in English, translated into Urdu and then backtranslated to English to remove any language ambiguities. It was pretested in a similar setting on $15 \%$ of the sample size population. The questionnaire was administered in Urdu by the principal investigator. Information was collected on sociodemographic variables, healthseeking behaviour and satisfaction level with health care services. The information about health-seeking behaviour was collected by asking 15 questions. Each question was scored as positive health-seeking behaviour and negative health-seeking behaviour. Each question had 1 mark for a correct answer and 0 for an incorrect answer. The cut-off level was $80 \%$; a score of $\geq 12$ out of 15 was considered positive health-seeking behaviour, a score $<12$ was considered negative health-seeking behaviour. Similarly, the scoring of satisfaction level with the health care services provided was based on 10 questions with a cut-off level of $80 \%$; a score of $\geq 8$ out of 10 was considered as satisfied, a score $<8$ was considered not satisfied.

\section{Ethical considerations}

The study was approval by the Institutional Review Board of Dow University of Health Sciences. Informed consent (verbal) was obtained from the participants and they were assured of the confidentiality of the information and 
that their treatment would not be affected if they declined to participate.

\section{Statistical analysis}

Data were analysed using SPSS, version 21. The frequencies, percentages, mean and standard deviation (SD) were calculated for continuous variables. In a multivariate logistic regression analysis, with the dependent variable being health-seeking behaviour, the crude and adjusted odds ratios (OR) and 95\% confidence intervals ( $\mathrm{CI}$ ) were calculated for the independent variables age, gender, marital status, educational status, visit cost and duration of HIV/ AIDS.

\section{Results}

\section{Sociodemographic characteristics of participants}

None of the individuals approached declined to participate (100\% response rate) Table 1 shows sociodemographic and health-related characteristics of the participants. The mean age of the respondents was 32.31 (SD 7.91) years with $71.4 \%$ aged between $36-60$ years. The majority were male $(76.9 \%)$ and married (81.9\%). Only $18.7 \%$ were educated but most were employed (75.8\%).

\section{Health-seeking behaviour of the participants}

Out of the total participants (182), $23.6 \%$ had positive health-seeking behaviour. Only $2.7 \%$ of the participants contacted health care professionals on noticing first symptoms of the disease

\begin{tabular}{|c|c|c|}
\hline Characteristic & No. & $\%$ \\
\hline \multicolumn{3}{|l|}{ Age (years) ${ }^{7}$} \\
\hline 18-35 & 52 & 28.6 \\
\hline $36-60$ & 130 & 71.4 \\
\hline \multicolumn{3}{|l|}{ Sex } \\
\hline Male & 140 & 76.9 \\
\hline Female & 42 & 23.1 \\
\hline \multicolumn{3}{|l|}{ Marital status } \\
\hline Married & 149 & 81.9 \\
\hline Single & 33 & 18.1 \\
\hline \multicolumn{3}{|l|}{ Literacy } \\
\hline Literate & 34 & 18.7 \\
\hline Illiterate(cannot read or write) & 148 & 81.3 \\
\hline Educational status $(n=34)$ & 34 & \\
\hline 5 years schooling & 4 & 11.8 \\
\hline 10 years schooling & 28 & 82.4 \\
\hline 12 years schooling & 2 & 5.9 \\
\hline \multicolumn{3}{|l|}{ Employment status } \\
\hline Employed & 138 & 75.8 \\
\hline Unemployed & 44 & 24.2 \\
\hline \multicolumn{3}{|l|}{ Hospital cost per visit (US\$) } \\
\hline$<5$ & 31 & 17.0 \\
\hline$\geq 5$ & 151 & 83.0 \\
\hline \multicolumn{3}{|l|}{ Years living with HIV } \\
\hline$<2$ & 82 & 45.1 \\
\hline$\geq 2$ & 100 & 54.9 \\
\hline
\end{tabular}

${ }^{\top}$ Mean $($ standard deviation $)=32.31(7.91)$ years .
(Table 2). Almost a third of the participants $(31.9 \%)$ reported the use of contaminated sharp equipment including razors and needles as a possible source of their infection. Only $8.8 \%$ of the participants reported that they were getting treatment on a regular basis. A majority (71.4\%) reported that they were facing problems in getting antiretroviral medicines and only $14.3 \%$ received medicine on a regular basis from the health care centre. The vast majority had considered going elsewhere for treatment with $28.0 \%$ reporting that they had received treatment from faith healers while receiving antiretroviral therapy. Regarding sexual contact with their partners in last 6 months, 30 (16.5\%) participants had had contact with only 2 of these reporting use of condoms. Most of the participants (91.2\%) reported that their family members knew that they were getting treatment for HIV infection. The majority $(84.1 \%)$ responded that people should first consult a doctor if they notice symptoms associated with HIV infection or AIDS.

\section{Satisfaction with health care facility and staff}

Based on our cut-off value of $>8$, over half of the participants (57.7\%) reported that they were satisfied with the health care services provided to them. The majority $(72.5 \%)$ were satisfied with the overall environment of the health centre but only $15.9 \%$ reported availability of drinking water at the centre and $16.5 \%$ reported that adequate seating arrangements were available (Table 3 ). Slightly under three-quarters of the participants (71.4\%) were satisfied with the attitude of the hospital staff, although $78.5 \%$ reported a communication barrier in discussing the symptoms of disease with the staff. Less than half of the participants $(44.5 \%)$ reported that staff answered their queries in detail, but $89.6 \%$ reported that theywere informed about the next follow-up visit by the hospital staff. Almost all of the participants (94.5\%) reported that they would 


\begin{tabular}{|c|c|c|}
\hline \multirow[t]{2}{*}{ Question } & \multicolumn{2}{|c|}{ Positive response } \\
\hline & No. & $\%$ \\
\hline 1. What did you do when you first noticed the symptoms? & 5 & 2.7 \\
\hline 2. How do you think you became infected with HIV? & 177 & 97.3 \\
\hline 3. Where did you go to receive treatment (source)? & 180 & 98.9 \\
\hline 4. Are you regularly taking medicines? & 16 & 8.8 \\
\hline 5. Are the medicines regularly available in your health centre? & 26 & 14.3 \\
\hline 6. Do you face any problems getting antiretroviral therapy? & 130 & 71.4 \\
\hline $\begin{array}{l}\text { 7. What else are you doing in terms of treatment other than taking antiretroviral } \\
\text { therapy? }\end{array}$ & 115 & 63.2 \\
\hline 8. If married, have you had sexual contact with your partner in the past few months? & 30 & 16.5 \\
\hline 9. If above is "yes", did you use a condom? & 2 & 6.7 \\
\hline 10. Have you considered going anywhere else for the treatment? & 166 & 91.2 \\
\hline 11. What are the advantages of going to different places for HIV/AIDS treatment? & 14 & 7.7 \\
\hline $\begin{array}{l}\text { 12. Have you told anyone in your family that you are coming to the hospital for } \\
\text { treatment? }\end{array}$ & 166 & 91.2 \\
\hline $\begin{array}{l}\text { 13. If someone has HIV/AIDS-related symptoms, what advice would you give to that } \\
\text { person? }\end{array}$ & 8 & 4.4 \\
\hline $\begin{array}{l}\text { 14. Are people with HIV/AIDS symptoms aware that there will be serious } \\
\text { consequences if they do not get treatment? }\end{array}$ & 31 & 17.0 \\
\hline $\begin{array}{l}\text { 15. Do you think people should consult a doctor/healthcare professional if he/she has } \\
\text { HIV/AIDS symptoms? }\end{array}$ & 153 & 84.1 \\
\hline
\end{tabular}

continue to receive treatment from the HIV/AIDS health care centre of the hospital.

\section{Univariate analysis}

Association of health-seeking behaviour of the participants with sociodemographic and health-related characteristics was determined in a univariate analysis. Health-seeking behaviour was dichotomized as positive and negative according to our cut-off values. No statistically significant association was found between age, sex, marital status, educational status, employment status and duration of HIV infection and health-seeking behaviour (Table 4). However, cost per visit was significantly associated with positive health-seeking behaviour (crude OR 2.91; 95\% CI: $1.28-6.59, P<0.01)$.

\section{Multivariate analysis}

In the multivariate analysis of the association between the independent variables and the dependent variable, positive health-seeking behaviour, the cost per hospital visit < US\$ 5 (adjusted
OR 4.49; 95\% CI: 1.80-11.21, $P<$ $0.001)$ and duration of HIV $<2$ years (adjusted OR 0.38; 95\% CI: 0.17-0.82, $P<0.02$ ) were significantly associated with positive health-seeking behaviour (Table 5).

\section{Discussion}

In our study there were more male than female participants, which is consistent with the findings of other studies conducted in Pakistan $(7,8)$. It could be that men are at higher risk of infection than women due to greater exposure to risk factors such as drug abuse and the use of contaminated syringes $(9,10)$, unprotected sexual activity with multiple partners (11) and unsafe blood transfusion probably because men in South Asia have more exposures outside the home. It could also be that women do not appear for diagnostic or screening tests and suffer in silence. The Pakistan Global AIDS Response Progress Report 2015 reported that of the estimated total of $91340 \mathrm{HIV}$-positive people in
Pakistan, 63872 were males and 27468 females, giving a male to female ratio of 2.3 (2). In our study the ratio was 3.3, so it may be that fewer women are seeking screening and treatment than men.

The majority of the participants in our study were employed, contrary to the findings of a study conducted in Peshawar Pakistan, which found that the majority of the respondents were unemployed (7). A study conducted in Argentina on anaemia among AIDS patients reported poverty and unemployment were significantly associated with being anaemic (12). A study in India on the sociodemographic profile of people with HIV attending a tertiary care hospital for antiretroviral therapy reported that more belonged to low socioeconomic classes as compared to middle and high socioeconomic classes (13).

The majority of the participants in our study were uneducated, which is similar to the findings in the Peshawar study and those reported from other parts of the world $(7,14)$. Level of education is an important factor as 


\begin{tabular}{|c|c|c|}
\hline \multirow[t]{2}{*}{ Question } & \multicolumn{2}{|c|}{ Positive response } \\
\hline & No. & $\%$ \\
\hline $\begin{array}{l}\text { 1. Is there a favourable environment at the health centre where you get your } \\
\text { treatment? }\end{array}$ & 132 & 72.5 \\
\hline 2. Is there portable drinking water available at the health centre? & 29 & 15.9 \\
\hline 3. Are there sufficient seating arrangements at the health centre? & 30 & 16.5 \\
\hline 4. Do the health care provider/hospital staff have a positive attitude towards you? & 130 & 71.4 \\
\hline 5. Have you faced any difficulties in talking to staff about your symptoms? & 143 & 78.5 \\
\hline 6. Have you felt disgrace while getting treatment at the hospital? & 165 & 90.7 \\
\hline 7. Do the staff give sufficient time to respond to your queries? & 81 & 44.5 \\
\hline 8. Do the staff inform you about your next visit? & 163 & 89.6 \\
\hline $\begin{array}{l}\text { 9. If above answer is "yes" then, did the staff inform you by giving an appointment } \\
\text { card? }\end{array}$ & 108 & 66.3 \\
\hline 10. Will you continue using the centre for treatment? & 172 & 94.5 \\
\hline
\end{tabular}

it determines knowledge about the disease. A study conducted in a postgraduate college of Rahim-Yar Khan, Pakistan reported that knowledge about HIV and AIDS was greater in students with 13 and 14 years of education as compared to those with 11 and 12 years (15). A multicentre study in Spain of an HIV-positive cohort reported that a greater proportion of the cohort had a low educational level (14). Less educated people were found at increased

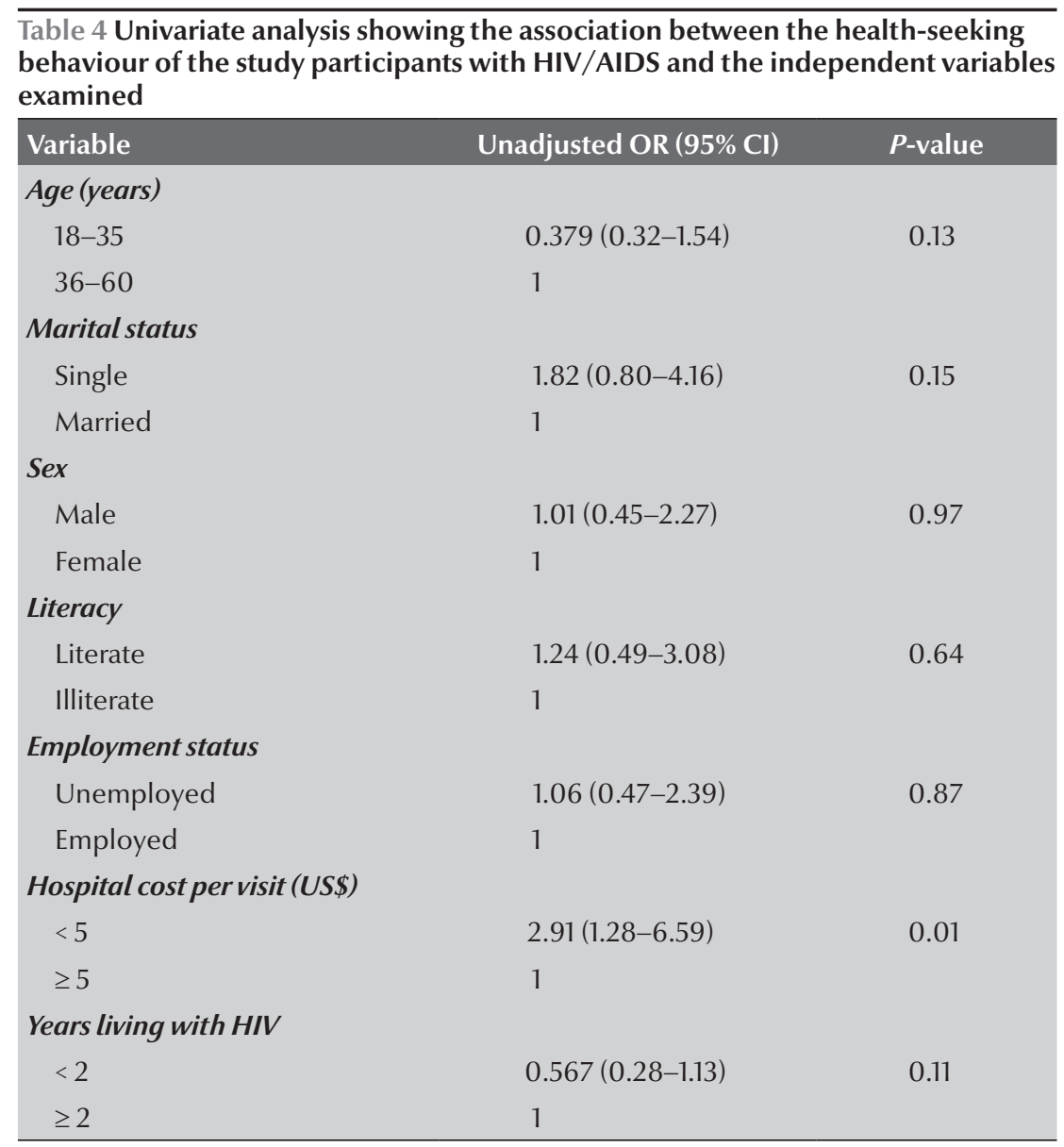

$O R=$ odds ratio; $C l=$ confidence interval.

risk of disease progression compared to more highly educated people and the risk of death was lower among those with a higher education level (14).

Other factors like early recognition of symptoms, utilization of health facilities and compliance with treatment, i.e. health-seeking behaviour, are as important and necessary for people living with HIV (16). The majority of our participants (76\%) with HIV/ AIDS showed limited health-seeking behaviour. The cost of treatment and duration of HIV infection were the only factors found significantly associated with health-seeking behaviour of the participants. The patients paying less than US $\$ 5$ per visit were about 4-times more likely to show positive healthseeking behaviour compared to those who paid more than US\$ 5 per visit. The patients living with HIV for less than 2 years duration showed an association with positive health-seeking behaviour. Studies conducted in India also found that the most common barrier to patient health-seeking behaviour and practice was cost $(17,18)$. A study conducted on the natural history of HIV in Chennai, South India reported that half of the individuals who discontinued treatment and then restarted the same therapy had initially discontinued due to cost, and $10 \%$ of patients stopped 


\begin{tabular}{|c|c|c|}
\hline Variable & Adjusted OR (95\% CI) & $P$-value \\
\hline \multicolumn{3}{|c|}{ Hospital cost per visit (US\$) } \\
\hline$<5$ & $4.49(1.80-11.21)$ & 0.001 \\
\hline$\geq 5$ & 1 & \\
\hline \multicolumn{3}{|c|}{ Years living with HIV } \\
\hline$<2$ & $0.38(0.17-0.82)$ & 0.02 \\
\hline$\geq 2$ & 1 & \\
\hline
\end{tabular}

$O R=$ odds ratio; $C I=$ confidence interval.

treatment within 4 months of initiation due to cost (18).

A person's health-seeking behaviour determines their actions when infection is suspected. If a person continues to have sexual contact even if he/she has recognized symptoms of the disease then they could infect more people thereby increasing the risk of epidemic. Self-treatment with antibiotics or other methods is another aspect of health behaviour which affects control of the disease. Such self-treatment and alternative methods can prolong the period of infectiousness prior to effective treatment and lead to the development of resistant strains (19). Social stigma, limited surveillance, voluntary counselling and testing systems, and a lack of knowledge among the general population and health practitioners can affect the health-seeking behaviour of people with HIV and in many countries these can result in underreporting of the disease.

Pakistan has been classified as a lowprevalence country for HIV/AIDS but the prevalence is increasing and needs the serious attention of both the public and private health sectors (2). Due to the stigma and discrimination associated with the infection, the majority of those positive for HIV do not seek further treatment and do not appear in the records. To address this problem, awareness and health promotion about HIV and AIDS in the general population is extremely important (15) as is improving the health-seeking behaviour of those living with HIV. The successful implementation of health promotion programmes can play a major role in controlling HIV and AIDS in Pakistan

There were some limitations to the study. The study was conducted in a single AIDS centre due to limited resources and time and findings can only be generalized to Karachi city. Its design is cross-sectional therefore temporal association between risk factors and outcome cannot be established.

\section{Conclusion}

The health-seeking behaviour of the majority of the HIV/AIDS participants in our study was generally poor and half of the patients were not satisfied with the services provided to them. The cost of treatment and duration of disease significantly predicted their healthseeking behaviour. Our study suggests that lower cost and timely treatment should be provided and efforts should be made to improve the health-seeking behaviour of people living with HIV/ AIDS.

\section{Funding: None.}

Competing interests: None declared.

\section{References}

1. Global report: UNAIDS report on the global AIDS epidemic 2013. Geneva: Joint United Nations Programme on HIV/AIDS (UNAIDS); 2013 (http://files.unaids.org/en/media/unaids/ contentassets/documents/epidemiology/2013/gr2013/UNAIDS_Global_Report_2013_en.pdf, accessed 15 November 2016).

2. Pakistan Global AIDS Response Progress Report (GARPR) 2015. Country Progress Report Pakistan. Islamabad: National AIDS Control Program, Ministry of National Health Services, Regulation and Coordination, Government of Pakistan; 2015 (http:// www.unaids.org/sites/default/files/country/documents/ PAK_narrative_report_2015.pdf, accessed 14 November 2016).

3. Mahal A, Rao B. HIV/AIDS epidemic in India: an economic perspective. Indian J Med Res. 2005;121:582-600. PMID: 15817965

4. Runganga AO, Sundby J, Aggleton O. Culture, identity and reproductive failure in Zimbabwe. Sexualities. 2001;4(3):315-32.
5. Pandey S, Singh SP, Shankar R, Sundar S. Treatment-seeking behaviour of HIV/AIDS patients around Varanasi. Indian J Prev Soc Med. 2009;40(1):108-11.

6. Price N. The performance of social marketing in reaching the poor and vulnerable in AIDS control programmes. Health Policy Plan. 2001;16(3):231-9. PMID: 11527863

7. Khan Y, Ali S, Zeeshan M, Khan Z. Demographic profile of HIVpositive patients registered at antiretroviral therapy centre Hayatabad Medical Complex, Peshawar. Khyber Med Univ J. 2013;5(3):152-5.

8. Khokhar O, Malik GJ, Khokhar N. Prevalence of HIV infection in a healthy population in Northern Pakistan. Rawal Med J. 2003;28(1):12-6.

9. Kwiatkowski CF, Booth RE. HIV risk behaviors among older American drug users. J Acquir Immune Defic Syndr. 2003;33:S131-7. PMID: 12853862

10. Hartel DM, Schoenbaum EE, Lo Y, Klein RS. Gender differences in illicit substance use among middle-aged drug users with or at risk for HIV Infection. Clin Infect Dis. 2006;43(4):525- 
11. Faisel A, Cleland J. Migrant men: a priority for HIV control in Pakistan? Sex Transm Infect. 2006;82(4):307-10. PMID: 16877580

12. Gonzalez L, Seley C, Martorano J, Garcia-Moreno I, Troncoso A. Infections and inequalities: anemia in AIDS, the disadvantages of poverty. Asian Pac J Trop Biomed. 2012;2(6):485-8. PMID: 23569955

13. Joge US, Deo DS, Lakde RN, Choudhari SG, Malkar VR, Ughade $\mathrm{HH}$. Sociodemographic and clinical profile of HIV/AIDS patients visiting to ART centre at a rural tertiary care hospital in Maharashtra state of India. Int J Biol Med Res. 2012;3(2):156872.

14. Monge S, Jarrín I, Pérez-Hoyos S, Ferreros I, García-Olalla $\mathrm{P}$, Muga R, et al. Educational level and HIV disease progression before and after the introduction of HAART: A cohort study in 989 HIV seroconverters in Spain. Sex Transm Infect. 2011;87(7):571-6. PMID: 21968461

15. Malik MR, Hussain A, Majid S, Iqbal MZ. Education, the only vaccine available for the control of HIV/AIDS. J Sheikh Zayed Med Coll. 2010;1(3):82-6.
16. Draft Protocol. A rapid assessment of health seeking behaviour in relation to sexually transmitted disease. 1995 (http://www. who.int/hiv/topics/en/HealthcareSeeking.pdf, accessed 14 November 2016).

17. Safren S, Kumarasamy N, James R, Raminani S, Solomon $\mathrm{S}$, Mayer KH. ART adherence, demographic variables and CD4 outcome among HIV-positive patients on antiretroviral therapy in Chennai, India. AIDS Care. 2005;17:853-62. PMID: 16120502

18. Kumarasamy N, Safran SA, Raminani SR, Pickard R, James $R$, Sri Krishnan AK, et al. Barriers and facilitators to antiretroviral medication adherence among patients with HIV in Chennai, India: A qualitative study. AIDS Patient Care STDs. 2005;19:526-37. PMID: 16124847

19. Kumarasamy N, Vallabhaneni S, Cecelia AJ, Yepthomi T, Balakrishnan P, Saghayam S, et al. Reasons for modification of generic highly active antiretroviral therapeutic regimens among patients in southern India. J Acquir Immune Defic Syndr. 2006;41:53-8. PMID: 16340473 